\title{
A educação financeira enquanto prática de autonomia financeira individual na escola básica
}

\author{
The financial education as a practice of individual financial \\ autonomy in basic school
}

\author{
Camila Labres Nemos ${ }^{1}$ \\ Mariana Lima Duro \\ Cláudia Brum de Oliveira Fogliarini Filha ${ }^{3}$
}

\begin{abstract}
Resumo: Nesta pesquisa tem-se como objetivo compreender a importância da educaçāo financeira enquanto prática libertadora para o desenvolvimento da autonomia financeira futura dos estudantes da escola básica, tendo como base as recomendaçōes da Base Nacional Comum Curricular (BNCC). Sabe-se que o ensino da matemática financeira nas escolas tem sido tratado como um conteúdo programático distante da realidade do aluno. Em contrapartida, a educaçāo financeira é mais ampla, e tem como propósito refletir sobre as finanças pessoais para o desenvolvimento da autonomia financeira. Em termos metodológicos, utilizou-se, além da pesquisa bibliográfica, a elaboraçāo e a execução de um projeto de educação financeira, baseado no empreendedorismo, em uma escola da rede pública estadual da cidade de Canoas/RS. Para verificar as aprendizagens geradas pela atividade, realizou-se entrevista semiestruturada com os participantes, antes e após sua aplicaçāo. Os resultados indicaram que os estudantes desenvolveram senso crítico em relaçāo às suas
\end{abstract}

Fecha de recepción: 15 de mayo de 2020. Fecha de aceptación: 24 de mayo de 2021.

${ }^{1}$ Instituto Federal de Educação, Ciência e Tecnologia do Rio Grande do Sul - Campus Canoas, camilanemos@gmail.com,orcid.org/0000-0002-3094-8754

2 Instituto Federal de Educaçāo, Ciência e Tecnologia do Rio Grande do Sul - Campus Canoas, mariana.duro@canoas.ifrs.edu.br, orcid.org/0000-0001-5492-4098

3 Instituto Federal de Educaçāo, Ciência e Tecnologia do Rio Grande do Sul - Campus Canoas, claudia.fogliarini@canoas.ifrs.edu.br, orcid.org/0000-0003-0575-2140 
finanças, compreendendo melhor os conceitos financeiros e sua importância. Pôde-se concluir que a educaçāo financeira é efetiva e importante para o desenvolvimento do letramento financeiro do aluno, porque demonstrou desenvolver habilidades financeiras nos participantes dessa pesquisa.

Palavras-chave: Educação Financeira na escola. Empreendedor de si mesmo. Base Nacional Comum Curricular (BNCC). Ensino e Aprendizagem de Matemática. Projeto na escola.

\begin{abstract}
The objective of this article is to understand the importance of financial education as a liberating practice in the development of the financial autonomy of basic school students, based on the recommendations of the BNCC. It is known that the teaching of financial mathematics in schools has been treated as a programmatic content, distant from the reality of the student. On the other hand, financial education is broader, and have as a purpose to reflect on personal finances for the development of financial autonomy. In methodological terms, beyond the bibliographical research, the elaboration and execution of a financial education project, based on entrepreneurship, in a public school in Canoas/RS. To verify the learning generated by the activity, a semi-structured interview was conducted with the participants, before and after their application. The results indicated that the students developed a critical sense of their finances, understanding better the financial concepts and their importance. It could be concluded that financial education is effective and important for the development of financial literacy of the student, because showed to develop financial skills in the participants of this article.
\end{abstract}

Keywords: Financial education in school. Self entrepreneur. Common National Curriculum Base. Teaching and learning of mathematics. Project in a school.

\title{
1 INTRODUÇĀO
}

Observa-se na prática, que o ensino da matemática financeira como conteúdo programático do ensino médio, desde antes da criação da Base Nacional Comum Curricular (BNCC) ser implementada, por muitas vezes, ocorre distante da vida cotidiana do aluno, já que o foco, geralmente, é o entendimento de conceitos 
descontextualizados, sem abordar a gestāo financeira pessoal do educando. Em contrapartida, entende-se a educação financeira de forma ampla com o propósito refletir também sobre conceitos da matemática financeira, porém voltados às finanças pessoais para que, desta forma, os estudantes desenvolvam sua consciência financeira, a qual resultará em um planejamento crítico de seus ganhos e gastos. Esta reflexão vem sendo realizada por alguns pesquisadores por meio de uma abordagem por projetos de educação financeira juntamente com o empreendedorismo, para formar cidadãos capazes de gerenciar suas finanças de maneira autônoma. Na sequência, um pouco mais sobre alguns destes pesquisadores que embasaram a parte teórica desta pesquisa.

Apesar de a educação financeira já fazer parte da Base Nacional Comum Curricular - BNCC (Brasil, 2018), documento que orienta o trabalho docente na educação básica, e da educação escolar como um todo, não se pode ignorar que ela se dá também, e mais evidenciada, pelos exemplos observados no meio familiar. Assim como enfatiza Pontes (2017), as crianças aprendem a consumir com sua família, como por exemplo, se a criança crescer vendo sua família endividada não aprenderá a economizar e, por consequência, possivelmente tornar-se-á um adulto endividado, com práticas de consumo exacerbadas. Assim, ao nāo terem contato com uma educaçāo financeira familiar, a escola passa a fazer um papel importante na vida de muitos jovens por tornar-se a instituição a qual abordará informaçōes financeiras básicas. Entretanto, muitos de seus conceitos - tais como juros, empréstimos, inflaçāo, investimento e economia mesmo na escola, por vezes não são discutidos ou não são explorados da melhor forma. Na maioria das vezes os conceitos financeiros são apresentados apenas como fórmulas matemáticas, sendo desconsiderada a sua aplicação no contexto do estudante e aplicando-os em situaçōes distantes da sua vivência, como por exemplo, finanças empresariais.

Além disso, o que geralmente é abordado nas escolas está longe de ser uma efetiva educação financeira, pois trabalha conceitos de matemática financeira completamente desconectados da vida do educando, fazendo com que o aluno perca o interesse em seu aprendizado, além de não conseguir fazer conexões com a prática. Assim, torna-se importante a discussāo dessa temática, já que, além de ser um tema contemporâneo e necessário nas escolas de educação básica, essa discussāo aflora com a criaçāo da BNCC (Brasil, 2018), que entrou em vigor no ano de 2019.

Dado esse contexto, neste trabalho tem-se como objetivo compreender a importância da educação financeira enquanto prática libertadora para o 
desenvolvimento da autonomia financeira futura dos educandos na escola básica. Ainda, visa-se apresentar dados acerca da aprendizagem de conceitos financeiros dos alunos, a partir de uma prática de educação financeira destinada a estudantes do ensino médio de uma escola estadual da cidade de Canoas/RS.

Tem-se como primeira hipótese que a educação financeira pode contribuir com o desenvolvimento do senso crítico do aluno para questōes financeiras, ou seja, que ela possibilita aos alunos compreender melhor os conceitos financeiros para que, desta forma, possam refletir antes de agir, organizando-se financeiramente. Como segunda hipótese, acredita-se que a educação financeira possa contribuir para o avanço do raciocínio lógico dos estudantes, à medida que passem a desenvolver métodos próprios e cada vez mais sistemáticos para a resolução de problemas que surgirem. Por fim, a terceira hipótese indica que a educação financeira contribui para o desenvolvimento autônomo e empreendedor do estudante, de modo a desenvolver sua independência para tomar suas decisōes financeiras.

Desta forma, a seguir, será discutido o que se entende por educação financeira neste trabalho. Além disso, será apresentado o cenário histórico que levou a educação financeira ser tema de discussão no meio escolar. Posteriormente, será apresentado um estudo, relatado por Silva e Powell (2013), a nível mundial, realizado pela Organização para a Cooperação e Desenvolvimento Econômico (OCDE), que ocorreu em 2003. Este estudo aborda dados relevantes para a discussāo da importância da educação financeira nas escolas, além de outros estudos que tragam a discussão de conceitos provenientes do empreendedorismo, para que se reflita acerca das ideias relacionadas à vida financeira individual do estudante, o conceito de empreendedor de si mesmo (Vargas, 2012), complementando com as indicações trazidas pela BNCC acerca da educação financeira nas escolas.

Por fim, serão apresentados dados sobre os conhecimentos prévios de matemática financeira de estudantes do ensino médio de uma escola da rede pública da cidade de Canoas/RS, comparados aos conceitos construídos após a realização de um projeto de educação financeira realizado com estes estudantes, para que se possa constatar ou refutar as hipóteses iniciais e as afirmaçōes levantadas pelos referenciais utilizados neste trabalho. Com isso, será possível analisar os resultados obtidos em termos conceituais após a aplicação prática da educação financeira vinculada com o empreendedorismo para a formação integral do estudante da escola básica no ensino médio. 


\section{REFERENCIAL TEÓRICO}

Ensinar é o processo pelo qual o professor e o aluno adquirem conhecimento a partir de conclusōes obtidas por meio das trocas de experiências individuais (Freire, 2014). Sendo assim, entende-se que a educação financeira é um conjunto de práticas que visam proporcionar uma reflexão crítica sobre as finanças pessoais para que, desta forma, quando considerada no contexto educacional, os estudantes desenvolvam sua consciência financeira. Nessa perspectiva, a criticidade pretendida através da educação financeira visa desenvolver a "capacidade de o indivíduo consumidor analisar e refletir acerca de tomadas de decisōes frente a uma sociedade líquido-moderna" (Rossetto, 2019, p. 22). Em concordância com Vargas (2012), entende-se que a educação financeira é uma proposta ampliada de observar o mundo. Ou seja, o sujeito, ao apropriar-se de conhecimentos na área financeira, torna-se capaz de compreender o consumo de forma geral, aprendendo a discernir quando é vantajoso ou nāo adquirir algo, considerando a necessidade da aquisição. Com isso, o sujeito apresenta-se preparado para tomar decisōes responsáveis na utilização do seu dinheiro, por saber analisar as vantagens e desvantagens do consumo no seu dia a dia.

Por vivermos em um país com o sistema capitalista, que visa maximizar o lucro, o consumo virou prioridade na vida dos cidadāos brasileiros. De acordo com Vargas (2012, p. 20) "o desejo, a vontade e os anseios sāo condiçōes essenciais para que o consumo seja reconhecido na atualidade". Logo, o consumo não é impulsionado apenas pela real necessidade de obter determinado produto ou serviço, mas também pelas ambiçōes individuais de cada ser humano. Entretanto, observa-se que muitos jovens ainda não conseguem se organizar financeiramente, e isso justifica a necessidade da educação financeira durante a formação escolar, já que muitos não têm acesso a este conhecimento por meio do seu contexto familiar ou de instituiçōes financeiras. Mais ainda, em concordância com Silva e Powell (2013), a educação financeira deve ser introduzida ainda no início da vida escolar das crianças porque, neste período, elas estão mais abertas a novos conhecimentos, oportunizando, com maior eficácia, a influência do comportamento financeiro futuramente.

A Organização de Cooperação e Desenvolvimento Econômico (OCDE) é uma organização mundial, formada por países com o PIB (Produto Interno Bruto) elevado que visa disseminar a Educação Financeira pelo mundo (Vargas, 2012). Segundo Silva e Powell (2013), a OCDE realizou em 2003 um projeto de educação financeira a nível internacional, o qual tinha como objetivo educar 
financeiramente a população de 34 países membros desta organização e de países que não eram membros, mas participaram do projeto, como por exemplo o Brasil. Como ponto de partida para a realização deste projeto, a organização desenvolveu um estudo, com os países envolvidos, a respeito do êxito obtido mediante a aplicação de projetos financeiros para a população local. O estudo apontou três situações significativas, relatadas por Silva e Powell (2013). Salientar-se-á, neste estudo, duas das três situações apresentadas pelos autores. A primeira situação afirma o crescimento no número de trabalhadores que deverão planejar suas economias pessoais a fim de financiar sua aposentadoria mais tarde; a segunda situação, que ganhará destaque aqui, aponta o endividamento de consumidores, principalmente jovens, devido ao modo inadequado de lidar com cartōes de crédito ou telefonia móvel, por exemplo.

Podemos observar que, em ambas as situaçōes, a educação financeira dos indivíduos é indispensável para evitar problemas. Desta forma, conforme a segunda situação constatada por meio da pesquisa realizada pela OCDE, compreende-se a importância de educar financeiramente e isso não envolve apenas a matemática financeira como conteúdo matemático obrigatório nas escolas, mas sim, a educação financeira indissociável do cotidiano do aluno. Do mesmo modo, a Base Nacional Comum Curricular (BNCC), aprovada pela resoluçāo CNE/ $\mathrm{CP}$ nㅇ 2, de 22 de dezembro de 2017, traz que

Há hoje mais espaço para o empreendedorismo individual, em todas as classes sociais, e cresce a importância da educaçāo financeira e da compreensão do sistema monetário contemporâneo nacional e mundial, imprescindíveis para uma inserçāo crítica e consciente no mundo atual (Brasil, 2018, p. 568).

Essa afirmação apresentada na BNCC vem ao encontro da discussāo realizada por Vargas (2012), que traz no seu estudo a proposta de projetos como base de formação para a educação financeira, trabalhada juntamente com o empreendedorismo. 0 objetivo da inserção dessa temática nas práticas educativas financeiras é discutido por Costa (2009), como auxiliar no processo de aprender a aprender, ou seja, o aluno torna-se construtor de seu próprio conhecimento, transformando-se em um empreendedor de si mesmo (Vargas, 2012).

Para compreender o termo aprender a aprender, cabe trazer a discussão feita por Becker (2012, p.33), o qual diz que "aprende-se porque se age e não porque se ensina, por mais que o ensino possa colaborar com essa atividade". Ou seja, para que realmente ocorra o processo de aprendizagem, deverá haver 
uma ação do indivíduo sobre o objeto a ser aprendido, pois a simples caracterização do objeto oriundo de outro sujeito não será suficiente para que o indivíduo compreenda a plenitude do que se deseja. Do mesmo modo, para que se possa compreender a expressão empreendedor de si mesmo (Vargas, 2012), deve-se entender que se trata daquele que consegue refletir sobre as suas açōes financeiras, para que se possa minimizar o consumo desenfreado.

Voltando aos aspectos destacados pela BNCC (Brasil, 2018), a educação financeira é tratada como um tema contemporâneo que afeta a vida do aluno de forma transversal e integrada e visa a abordagem desta temática nas escolas de maneira contextualizada. Também é prevista como um tema que pode e deve ser trabalhado de forma interdisciplinar, trazendo conceitos de matemática financeira e aprofundando-os com o estudo da economia e/ou história, por exemplo. Sobre educação financeira, a BNCC (Brasil, 2018) traz o seguinte:

Essa unidade temática favorece um estudo interdisciplinar envolvendo as dimensōes culturais, sociais, políticas e psicológicas, além da econômica, sobre as questōes do consumo, trabalho e dinheiro. É possível, por exemplo, desenvolver um projeto com a História, visando ao estudo do dinheiro e sua função na sociedade, da relaçāo entre dinheiro e tempo, dos impostos em sociedades diversas, do consumo em diferentes momentos históricos, incluindo estratégias atuais de marketing. Essas questōes, além de promover o desenvolvimento de competências pessoais e sociais dos alunos, podem se constituir em excelentes contextos para as aplicaçōes dos conceitos da Matemática Financeira e também proporcionar contextos para ampliar e aprofundar esses conceitos. (Brasil, 2018, p. 269)

As afirmaçōes descritas no trecho destacado da BNCC sobre educação financeira indicam que essa é uma temática importante a ser desenvolvida no âmbito escolar, em especial pelo fato da interdisciplinaridade da temática, o que torna esse estudo mais contextualizado para o aluno. Entretanto, os conceitos abordados na BNCC possuem um nível de complexidade. Tais conceitos são abordados em curso de graduação e, agora, propostos a alunos da educação básica como um desafio a ser atingido através da educação financeira (Hofmann, 2020). Deste modo, a aplicabilidade da matemática financeira torna-se mais visível e, juntamente com a educação financeira e com outros conteúdos abordados, ajudarão a viabilizar a formação integral do aluno. Por isso, torna-se necessário a educação financeira escolar, mas também o apoio familiar. 
Para compreender a importância da educação financeira na escola básica, apresentaremos, na próxima seção, a metodologia utilizada para responder aos questionamentos deste estudo, descrevendo o avanço conceitual dos estudantes sobre a temática, a partir da prática de educação financeira. Além disso, esse artigo aborda o estudo da educaçāo financeira escolar, logo nāo aprofundar-se-á a investigação da educação financeira oriunda do núcleo familiar.

\section{METODOLOGIA}

A realização deste trabalho foi dividida em quatro partes, sendo a primeira uma pesquisa bibliográfica. Como foi definido por Pizzani e colaboradores (2012, p.54), a pesquisa bibliográfica é "a revisão da literatura sobre as principais teorias que norteiam o trabalho científico", ou seja, através da pesquisa bibliográfica pode-se compreender o que os outros autores dissertam sobre determinado assunto. Neste caso, pretendeu-se entender o que alguns pesquisadores falam sobre educação financeira, empreendedorismo e pedagogia construtivista, assuntos que embasaram a discussão sobre a importância de educar financeiramente os jovens dentro das escolas.

Esta parte da pesquisa foi realizada de maneira não sistemática, a partir da busca pelas palavras-chave "educação financeira" e "empreendedor de si mesmo" no portal de periódicos da CAPES e no Google Acadêmico. Para a seleção das leituras que seriam realizadas, considerou-se os resumos dos trabalhos, buscando identificar os que abordassem a educação financeira destinada a crianças e adolescentes na escola básica, resultando em cinco trabalhos encontrados. Outras leituras, como os documentos norteadores da educação básica, foram diretamente selecionadas para embasar o estudo feito e três outras leituras também foram utilizadas como referência nesta pesquisa, sendo elas: Costa (2009), Vargas (2012) e Becker (2012), por serem consideradas pesquisas importantes para o embasamento deste trabalho. Posteriormente, foram selecionadas mais três leituras a fim de complementar a pesquisa.

Para a segunda etapa deste trabalho, realizou-se uma entrevista semiestruturada sobre os conhecimentos financeiros de estudantes do ensino médio. Na sequência, a terceira etapa consistiu no desenvolvimento de uma oficina prática de educação financeira, para que, na quarta etapa, dada pela reaplicação da entrevista inicial aos participantes, pudessem ser observados os possíveis avanços de compreensão de conceitos financeiros dos estudantes. 
A oficina foi desenvolvida durante 11 encontros de 40 minutos cada, sendo ofertada para 12 alunos do ensino médio de uma escola da rede estadual da cidade de Canoas. Ela foi elaborada de modo que os estudantes participassem em grupos e, com o auxílio de um ministrante para cada grupo, desenvolvessem um produto ou um serviço a ser ofertado por eles. Os conceitos trabalhados nesta oficina foram: receita, lucro, custo, função receita, montante, capital, juros, empréstimo, capital de giro, inflação, rentabilidade da poupança e investimento. Durante os encontros, os estudantes foram desenvolvendo cálculos e estratégias para obter os valores de venda de seus produtos ou serviços, de acordo com a realidade de cada grupo e a partir dos conceitos trabalhados na oficina, de forma a gerar algum tipo de benefício social. Ou seja, os estudantes possuíam autonomia para, a partir do produto ou serviço escolhido por cada grupo, construir os conceitos citados anteriormente. Para que o conceito fosse compreendido de forma adequada, o ministrante de cada grupo conduzia a discussão a fim de provocar uma reflexão sobre o conceito e sobre o que os alunos precisariam para continuar sua empresa. Isso guiado previamente por uma apostila criada para ser completada pelos estudantes com as informaçōes do seu produto ou serviço. Assim, a oficina de educação financeira foi construída de forma que os alunos pudessem refletir e construir suas próprias definiçōes sobre os conceitos abordados, porém sempre com o auxílio do ministrante para que alcançassem a compreensão correta. Isso porque "têm-se indícios significativos de que a compreensão de noçōes econômicas é um processo de construção elaborado" (Hofmann; Soares, 2015, p. 263). Destaca-se que para o desenvolvimento dessa pesquisa, todos os alunos e seus responsáveis legais assinaram um termo de consentimento.

Cabe ressaltar aqui que os encontros não tiveram como objetivo preparar os estudantes para gerenciar um empreendimento. O objetivo era utilizar-se do empreendedorismo para estimular os estudantes a pensarem sobre conceitos que estão presentes no seu dia a dia e que influenciam diretamente na sua vida financeira. Exemplo disso é a reflexão feita sobre o valor da hora trabalhada, a partir do salário mínimo. Também pode-se citar aqui o capital de giro em que, para definir o seu valor, os estudantes tiveram que pensar sobre possíveis imprevistos que pudessem acontecer consigo, dando ênfase para a importância de se ter uma reserva financeira para essas situaçōes.

Este último exemplifica a discussāo trazida por Vargas (2012), de que a educação financeira tem o propósito de propiciar a melhora na qualidade de vida dos estudantes, bem como instruí-los para que melhorem sua conduta financeira individual, gerando efeitos para o seu entorno familiar e social. Além 
disso, para completar a justificativa acerca do objetivo que se propōe de nāo ser empreendedor no sentido capitalista -o qual visa maximizar o lucro em cima do consumidor-, os estudantes tiveram que pensar em um benefício social, mantendo preço, mesmo que fictício, acessível à comunidade escolar em que se encontravam. A ideia do benefício social surgiu como uma forma de fazer com que os estudantes utilizassem da sua criatividade para produzir algo pensando no bem comum.

Para serem obtidos os dados acerca da aprendizagem dos estudantes ao longo desta oficina, foi preparada uma entrevista semiestruturada, com 19 perguntas. Esta entrevista foi aplicada com 10 alunos participantes da oficina, antes de iniciar os encontros e após a finalização dos mesmos para analisar a compreensão dos estudantes acerca de conceitos trabalhados nos encontros. Para possibilitar a degravação de suas falas, utilizou-se o recurso da gravação em áudio das respostas e, concomitante ao processo de gravação, transcreveu-se as respostas durante a entrevista para o arquivamento e análise posterior. Assim, as respostas da pergunta inicial e final foram separadas em categorias, de modo a compreender o avanço conceitual obtido pelos estudantes participantes da oficina.

A análise das respostas dadas pelos estudantes foi prioritariamente qualitativa, possibilitando a identificação de conceitos academicamente "adequados" ou "inadequados". A classificação entre "conceito adequado" e "conceito inadequado" foi realizada pela análise das aplicaçōes referidas pelos estudantes, a partir do que o meio acadêmico define sobre os conceitos abordados na oficina, citados anteriormente. As respostas divergentes foram elencadas como inadequadas, mesmo quando mal aplicadas. A análise qualitativa foi aplicada quando nāo foi possível separar as respostas em conceitos adequados e inadequados, mas que traziam uma abordagem pertinente para traçar o desenvolvimento conceitual do educando. Para cada questão, observou-se a quantidade de respostas que partiram de ideias inadequadas ou mal aplicadas, que os alunos traziam na primeira entrevista, e que avançaram para ideias adequadas, ou melhores aplicadas, na segunda entrevista.

Uma primeira análise dessa quantidade gerou um percentual de avanço para cada questionamento, ou seja, analisou-se individualmente as respostas apresentadas de cada um dos 12 questionamentos na primeira entrevista e dos mesmos 12 questionamentos conceituais na segunda entrevista. Quando analisadas as respostas da primeira entrevista, observou-se aquelas que apresentavam o referido conceito de forma errônea, quantificando-as. Após a análise individual das perguntas da primeira entrevista, foram quantificadas, na 
segunda entrevista, as respostas que passaram a ser compreendidas de forma adequada, e que não eram compreendidas inicialmente. Essas quantidades resultaram em um percentual de avanço em cada conceito questionado. Esse percentual indica quantos por cento de estudantes participantes passaram a compreender os conceitos de forma adequada. Após o cálculo individual de percentuais de avanço, foi realizada a média aritmética simples dos percentuais encontrados. Dessa forma, pôde-se analisar, individualmente cada uma das 12 perguntas em ambas entrevistas, de cada um dos 10 estudantes envolvidos (totalizando 240 respostas analisadas), a fim de encontrar avanços conceituais pertinentes para compreender, através da média aritmética simples, se o modo como foi proposta a oficina de educação financeira gerou resultados positivos para a compreensão conceitual. As respostas às demais perguntas foram analisadas qualitativamente, com o propósito de entender o desenvolvimento conceitual dos estudantes. Os alunos participantes nāo foram identificados, por isso, estão denominados por letras do alfabeto.

\section{RESULTADOS E DISCUSSÕES}

Após a análise dos avanços conceituais, obtidos através das duas entrevistas, inicial e final, pôde-se perceber que, de forma geral, os estudantes apresentaram 56\% de avanços, em média. Ou seja, mais da metade dos conceitos que não eram compreendidos inicialmente pelos estudantes, passaram a ser compreendidos ao final da oficina. Vale ressaltar que os alunos que inicialmente haviam respondido adequadamente o referido conceito na primeira entrevista, mantiveram suas respostas e, em alguns casos, pôde-se notar ainda um avanço na certeza com a qual aquele conceito foi respondido após a oficina. Para chegar nesta porcentagem, considerou-se 12 perguntas do questionário, as quais tratavam de conceitos discutidos ao longo da oficina. Abaixo serāo descritos os objetivos de cada questão e a análise das respostas obtidas.

\section{- Pergunta 1: Qual CarReira os estudantes PRETENDEM SEGUIR NO FUtURO.}

Esta pergunta foi desconsiderada para a análise dos dados, pois observou-se que os participantes mantiveram a mesma resposta em ambas as entrevistas. Além disso, ela serviu apenas para conhecer melhor os integrantes da oficina. 


\section{- Pergunta 2: 0 Que os estudantes fariam Para ter uma Renda eXtra.}

Na primeira vez que foram entrevistados, 3 estudantes responderam coisas relacionadas à venda de um serviço, como por exemplo, o aluno J que respondeu: "Difícil. Faria alguma coisa para fazer na rua, um serviço de carro etc. Começaria a falar com alguém para traçar um plano para arrecadar dinheiro". Sete estudantes optaram pela venda de um produto, como por exemplo, o aluno $\mathrm{D}$, que respondeu que "faria coisas de comer para vender, doces, bolos etc.". Já na segunda entrevista, houve uma pequena alteração na preferência destas escolhas pelos alunos. Sendo assim, 2 estudantes optaram por comercializar um serviço, 7 estudantes optaram por vender um produto e um optou por ter uma renda extra através de investimentos financeiros em criptomoedas - "Faria investimentos com curto prazo de recebimento. Investiria um valor x para ter mais dinheiro todo final do mês e mais minha renda fixa. [...] Estudaria uma empresa que fosse boa para a aplicação" - Aluno E.

Dentre os estudantes que optaram por obter uma renda extra por meio da venda de um serviço quando questionado na primeira entrevista, um estudante manteve sua ideia na segunda entrevista; outro estudante mudou para a venda de produto, possivelmente por ter trabalhado com a venda de produtos durante a realizaçāo da oficina; e outro ainda mudou para investimentos em criptomoedas, possivelmente por ter discutido o tema durante as oficinas e ter se interessado mais pelo assunto que já era de seu conhecimento. Houve um aluno que mudou da venda de produtos, na primeira entrevista, para a venda de serviços, na segunda entrevista, e sua mudança pode ser justificada pelo desconhecimento que este aluno tinha no início da oficina em relação à venda de serviços, que foi questionada ao longo da oficina.

Acredita-se que há esta diferença entre as preferências de escolha dos alunos para a venda de produtos e de serviços, visto que haja um desconhecimento dos alunos para calcular o preço de um serviço. Por outro lado, torna-se bem mais fácil vender um determinado produto, pois ficam mais claros os gastos envolvidos, sendo mais perceptível o valor que deverá ser cobrado para a sua venda. Somente um dos grupos de alunos participantes desta oficina trabalhou com a venda de serviço, os demais não tiveram contato com as mesmas formas de reflexāo que definiram os valores atribuídos à venda do serviço escolhido. Por isso, acredita-se que a preferência pela comercialização de serviços manteve-se baixa. 


\section{- Pergunta 3: como os estudantes conceituavam "Lucro".}

Para analisar as respostas desta pergunta, elas foram divididas em quatro categorias, são elas: a) lucro entendido como receita, ou seja, o lucro é todo o valor obtido na venda de um produto ou um serviço; b) lucro entendido como uma porcentagem, ou seja, deve-se estipular um percentual sobre o custo para a produção de determinado produto ou serviço para se obter o valor do lucro; c) lucro entendido como valor destinado a investir, ou seja, o lucro é o valor monetário que sobra para se investir em algo; e d) lucro entendido como o valor da receita menos o valor do custo de um produto ou um serviço. Desta forma, a categoria (a) enquadra-se nos conceitos inadequados de lucro, pois não considera o gasto obtido para a produção do que se oferta. Já as categorias (b), (c) e (d) enquadram-se nos conceitos vistos como adequados, além de serem conceitos trabalhados ao longo das oficinas.

Percebeu-se que, na primeira entrevista, 2 alunos enquadraram-se na categoria (a), ao dizer que lucro "é quando você está recebendo pelo que está fazendo" - aluno J. Em contrapartida 2 alunos entendiam lucro como a categoria (b) - "[...] o lucro seria um ganho que tu tira, digamos que eu compre essa caneta por 1 real, se eu vendesse ela por 2 reais eu vou ganhar cem por cento." aluno $\mathrm{I}^{4}$-e 6 alunos entendiam lucro como a categoria (d)- "Iucro é receita menos despesa" aluno B. Na segunda entrevista, um aluno manteve a resposta que se encaixa na categoria (a). Um aluno manteve o conceito de lucro enquadrado na categoria (b), 2 alunos passaram a entender lucro como investimento (categoria c) - "É o dinheiro que tu usas pra investir" aluno I - e 6 alunos mantiveram-se compreendendo o lucro como a categoria (d).

De forma geral, 8 alunos tinham a compreensão adequada de lucro na primeira entrevista. Já na segunda entrevista, um aluno conseguiu compreender melhor este conceito e responder adequadamente. Dentre os 8 que mantiveram a resposta correta, pode-se perceber que alguns estudantes trocaram de categoria, pois passaram a compreender o conceito de lucro de maneira mais ampla.

4 Optou-se por manter a escrita como o estudante relatou, mesmo estando, em alguns casos, gramaticalmente incorreto. 
- Pergunta 4: compreender se os alunos sabiam diferenciar produto de SERVIÇO.

Foram criadas duas categorias de respostas, sendo elas: (a) o serviço é a mão de obra e o produto é algo a ser vendido; e (b) não soube responder. A categoria (a) tem o conceito adequado da diferenciação entre produto e serviço.

Na primeira entrevista, 7 estudantes enquadraram-se na categoria (a) - "Serviço é mão de obra, por exemplo eu que sou parte do serviço. Produto é o que a gente vende, o motivo do serviço" aluno A -, ou seja, já compreendiam a diferença entre produto e serviço. Em contrapartida, 3 alunos não souberam responder o questionamento, pois não sabiam diferenciar produto de serviço e então enquadraram-se na categoria (b). Na segunda entrevista, todos os 10 estudantes souberam a diferença entre produto e serviço e enquadraram-se na categoria (a). Obteve-se como conclusāo o avanço conceitual de todos os estudantes que haviam respondido de forma inadequada ou incompleta na primeira entrevista.

\section{- Pergunta 5: compreender como os estudantes calculam o lucro de um produto e de um serviço.}

Várias dimensōes surgiram como resposta, dentre elas estão: (a) o lucro deve ser calculado através do preço de mercado do produto ou serviço - "Teria que ver dependendo do produto, me baseando no mercado", aluno D -; (b) deve ser estimada a porcentagem que se quer obter de lucro sobre o custo do produto ou serviço ofertado - "Eu calculo tudo o que eu tenho de gastos e quanto que eu vou ganhar em cima disso, eu tenho que ganhar mais de 100\% do que eu gasto", aluno G -; (c) deve ser calculada a diferença entre receita e custo para obter-se o lucro - "Diminuiria o custo do valor do produto", aluno I -; (d) o lucro é entendido pelo cálculo do custo do produto ou serviço - "Faria o gasto que eu teria para produzir, energia elétrica, energia física, transporte, e é isso", aluno E -; e (e) o lucro é entendido como receita, ou seja, o valor de venda do produto ou serviço ofertado - "Tem que ver o que eu comprei e somar. Não sei, normalmente a pessoa diz 'te pago tanto'", aluno $\mathrm{F}$-. Os conceitos adequados para calcular-se o lucro de um produto ou um serviço são os conceitos que se enquadram nas categorias (b) e (c). 
Na primeira entrevista, percebeu-se que 5 dos 10 alunos já tinham o conceito do cálculo do lucro de um produto formado adequadamente, enquanto 4 dos 10 alunos tinham o conceito do cálculo do lucro de um serviço formado adequadamente. Porém, na segunda entrevista, as respostas obtidas por 9 dos 10 alunos foi uma das duas dimensōes adequadas para o cálculo do lucro de um produto. Para o serviço, 7 dos 10 alunos responderam uma das duas dimensões corretas enquanto 3 responderam que o lucro do serviço deve ser calculado através do preço de mercado e 1 aluno respondeu que o cálculo do lucro deveria ser realizado através do cálculo do custo (dimensão d).

Acredita-se que os alunos tenham compreendido melhor a ideia de lucro para produto, considerando que a maior parte dos grupos trabalhou com a venda de produtos em vez de serviços. Apesar de ser feita uma abordagem sobre o cálculo de serviço com todos os grupos, pode-se explicar este fenômeno através da pedagogia construtivista, teoria defendida por Becker (2012), em que se discute a ideia de que o aluno constrói sua aprendizagem na ação sobre objeto que está sendo estudado. Nesse caso, provavelmente isso não ocorreu com este estudante que não soube ressignificar o conceito.

\section{- Pergunta 6: COMPReEnder como os alunos conceituam custo.}

Para isso, dividiu-se as respostas em 3 dimensões: (a) custo visto como receita, ou seja, quanto o cliente paga por determinado produto ou serviço; (b) custo entendido como o quanto se paga para produzir determinado produto ou serviço (o conceito adequado de custo) e (c) não soube responder.

Na primeira entrevista, 3 alunos entendiam custo como receita (dimensão a) - "Sim, é o valor do material que você está vendendo. O quanto têm de custo em cima. A mão de obra, a matéria prima, e o tempo gasto", aluno $\mathrm{H}$-, 6 entendiam custo como o conceito adequado de custo (dimensão b) e 1 não soube responder (dimensāo c). Na segunda entrevista, 2 mantiveram sua compreensão de custo como receita (dimensāo a) e os outros 8 passaram a entender custo como o conceito da dimensão b - "É o valor que tu gasta para produzir o produto ou fazer o serviço", aluno I -.

Obteve-se como conclusão o avanço conceitual de dois dos quatro estudantes que haviam respondido de forma inadequada ou incompleta na primeira entrevista. 
- Pergunta 7: analisar o raciocínio desenvolvido pelos estudantes sobre O MODO COMO FAZEM PARA CALCULAR O CUSTO DE UM PRODUTO OU UM SERVIÇO.

Para isso, obteve-se as seguintes dimensōes: (a) os alunos compreendiam que o custo era calculado através da soma dos gastos; (b) o cálculo do custo foi identificado como o cálculo da receita, ou seja, o valor do produto ou do serviço vendido; (c) não soube responder; e (d) o cálculo do custo foi compreendido como o cálculo do lucro.

Na primeira entrevista, três alunos entendiam o cálculo do custo como a dimensão (a) - "Acho que custo é tudo que tu vai usar para [realizar] aquele serviço, se é de transporte tem gasolind", aluno B -, ou seja, já compreendiam a forma adequada de calculá-lo. Enquanto isso, três alunos entendiam o cálculo do custo como receita, ou seja, o preço de venda do produto ou serviço comercializado (dimensão b) - "Eu ia ver quanto deu mais ou menos para fazer e colocar um pouco a mais, a mão de obra no caso", aluno F -, três alunos não souberam responder (dimensão c) e 1 aluno entendia custo como lucro (dimensão d) - "Primeiro tu apontas os valores que tu gastaste e o que arrecadou no final e subtrai", aluno I -. Na segunda entrevista, nove estudantes passaram a compreender o cálculo do custo como a soma dos gastos para produzir determinado produto ou serviço e um aluno continuou compreendendo o cálculo do custo como receita.

Logo, pode-se perceber que, em geral, os estudantes conseguiram compreender melhor como calcular o custo de determinado produto ou serviço. A compreensāo deste conceito e do seu cálculo é considerada fundamental para o desenvolvimento da autonomia financeira do participante da oficina, já que traz a possibilidade de uma reflexão crítica sobre o quanto se deve gastar para produzir um produto ou oferecer um serviço de qualidade, considerando o orçamento previamente calculado. Como atesta Vargas (2012) em um material criado para educar-se financeiramente, a educação financeira deve servir para que o educando possa autogovernar-se e autocriticar-se em suas práticas de consumo, para que as mesmas não se tornem acentuadas. Obteve-se como conclusão o avanço conceitual de seis dos sete estudantes que haviam respondido de forma inadequada ou incompleta na primeira entrevista. 


\section{- Pergunta 8: compreender como os alunos determinam o preÇO de VENDA (RECEITA) DE UM PRODUTO OU SERVIÇO.}

Para essa questão, dividiu-se as respostas em três dimensões: (a) conforme o conceito de custo deve-se incluir o valor da mão de obra; (b) através da pesquisa de mercado, ou seja, determinando um valor aproximado dos valores cobrados por produtos ou serviços parecidos que são ofertados e (c) conforme o conceito de receita definido durante a oficina, ou seja, o preço de venda do produto e do serviço.

Na primeira entrevista, três alunos responderam que o preço de venda de um produto deve ser estipulado através do custo, incluindo a mão de obra (dimensão a) - "Ia ver o que gastei para fazer mais a mão de obrd", aluno F -. Um aluno respondeu que seria determinado através do preço de mercado (dimensāo b) - "Eu vejo a média do mercado, tento colocar abaixo, mas com um valor que pague o meu transporte e um pouco de lucro para mim, não precisa ser muito, mas tem que me dar retorno", aluno $\mathrm{H}$-, enquanto seis alunos responderam que seria calculado através do conceito de receita, ou seja, o valor do custo mais o lucro (dimensão c) - "Eu veria o que eu vou lucrar com aquilo, pois eu teria que colocar um preço a mais pelo que a gente pagou. Pois nós compramos sem imposto, e nós mesmos colocamos o imposto", aluno A -, a qual determina o conceito adequado de receita. Já na segunda entrevista, três alunos mantiveram sua resposta como custo com a mão de obra (dimensão a) e 7 passaram a compreender o preço de venda de um produto como receita (dimensão c) - "Além do que citei (custos com a mão de obra), contratempos, quebra de produtos, lucro extra para pagar isso e um lucro para mim", aluno E -.

Logo, podemos perceber que houve um avanço pequeno na compreensāo deste conceito. Porém, como o objetivo principal da oficina de educaçāo financeira nāo é formar empreendedores, mas sim empreendedores de si mesmo (Vargas, 2012), o desenvolvimento deste conceito ao longo dos encontros serviu para que os educandos pudessem refletir criticamente acerca dos cálculos orçamentários pré-estabelecidos, considerando os gastos obtidos para a produção do que por eles foi proposto e assim compreender que um bom planejamento prévio contribui para estabilidade financeira. Obteve-se como conclusāo o avanço conceitual de um dos quatro estudantes que haviam respondido de forma inadequada ou incompleta na primeira entrevista. Entende-se que não houve mais avanços em relação a este conceito, visto que os estudantes que mantiveram suas respostas não demonstraram interesse em trabalhar com um produto 
ou serviço de forma que eles tivessem que determinar a receita do mesmo. Logo, o conceito de receita ficou associado ao conceito de custo, que é o conceito de maior contato, ou seja, o custo de um produto ou um serviço que querem adquirir para si. Como as perguntas da segunda entrevista foram mantidas como as da primeira, se fosse especificado que este conceito deve ser respondido considerando o ponto de vista trabalhado durante a oficina, provavelmente os alunos compreenderiam melhor o que deveria ser respondido, resultando em um percentual maior de avanços. Em uma possível continuidade de aprofundamento dos conceitos em novas oficinas, esse tema poderia ser tratado de maneira mais detalhada, dado que o conceito de receita pode abranger diferentes significados em cada contexto aplicado.

\section{- Pergunta 9: COMPREender o MeSmo CONCEITO da PERGUNTA ANTERIOR, PORÉM DESTINADA A SERVIÇOS, OU SEJA, OS ALUNOS FORAM QUESTIONADOS ACERCA DO DESENVOLVIMENTO DO CÁLCULO DO PREÇO DE VENDA DE UM SERVIÇO.}

Obteve-se quatro dimensōes, das quais as dimensōes (a) e (b) possuem uma conceituação inadequada: (a) o preço de venda definido como o valor do custo de um serviço, ou seja, o valor da mão de obra; (b) o preço é estabelecido através do preço de mercado; (c) o estudante não soube responder e (d) o valor de venda do serviço segue o conceito de receita, ou seja, preço de custo mais o lucro.

Na primeira entrevista, os dez alunos compreendiam o cálculo do preço de venda de um serviço como custo (dimensão a) - "Acho que pelo tempo que demorasse para ser feito", aluno J -, analisando o preço de mercado (dimensão b) - "Eu veria quanto as pessoas estão cobrando e faria o mesmo", aluno $\mathrm{F}$ - ou não soube responder (dimensão c). Já na segunda entrevista, quatro alunos passaram a compreender o cálculo do preço de venda como custo mais lucro, ou seja, o conceito adequado trabalhado nos encontros (dimensāo d) - "Teria que fazer uma pesquisa pra saber os valores de edição, tempo, horas trabalhadas, número de funcionários e equipamentos", aluno C-. Essa pouca mudança na compreensão do cálculo deve-se ao fato de apenas um grupo ter trabalhado com a venda de serviços, ou seja, conforme Freire (2014), este grupo pôde experienciar melhor a reflexão crítica e, por consequência, construir um conhecimento específico em cima deste conceito trabalhado. Obteve-se como conclusão o avanço conceitual de quatro dos dez estudantes que haviam respondido de forma inadequada ou incompleta na primeira entrevista. 


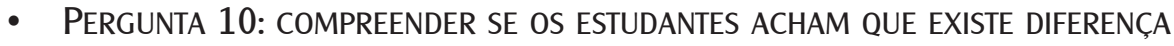 PARA CALCULAR O PREÇO DE VENDA DE UM PRODUTO E DE UM SERVIÇO.}

Este questionamento foi desconsiderado na análise dos dados, pois apenas um grupo optou por refletir acerca dos processos envolvidos para a venda de serviços. A falta destas discussōes explica-se pela falta de tempo disponível para a realização de cada encontro.

\section{- Pergunta 11: compreender Se os alunos sabiam conceituar o que é JuRos.}

As respostas foram divididas em duas dimensōes, sendo elas: (a) a remuneração paga pelo empréstimo do dinheiro, que é uma conceituação adequada de juros e (b) não souberam responder.

Na primeira entrevista, as respostas dadas por sete, dos dez, alunos condizem com a dimensão (a) -"Sim, tu pede dinheiro emprestado e tem uma porcentagem para ganhar em cima, tipo o Sistema Price", aluno B-, em que juros é visto como a remuneração dada pelo dinheiro pego emprestado. Em contrapartida, três alunos não souberam responder ao questionamento feito (dimensão b). Na segunda entrevista, nove alunos responderam o conceito de juros conforme a dimensão (a), enquanto, apenas um continuou sem saber responder o questionamento (dimensão b).

Escolheu-se trabalhar o conceito de juros durante esta oficina, pois, assim como Becker (2012) e Freire (2014) discutem ao longo de suas obras, discutir com os alunos um conceito que já faz parte de suas vidas, enquanto cidadãos e enquanto consumidores, já que todos os participantes entrevistados praticavam uma atividade remunerada, facilita o aprendizado deste conceito. Desta forma, um dos objetivos propostos é que fosse aproximada a matemática trabalhada em sala de aula de conceitos que já são vivenciados pelos educandos. Assim, consegue-se despertar a curiosidade proveniente do estudante acerca de conceitos que, talvez, não eram bem compreendidos, mas que fazem parte do seu cotidiano. Obteve-se como conclusão o avanço conceitual de dois dos três estudantes que haviam respondido de forma inadequada ou incompleta na primeira entrevista.

- Pergunta 12: compreender o que os alunos entendem sobre montante.

As respostas foram divididas em duas dimensōes, sendo elas: (a) o aluno compreendeu adequadamente o conceito de montante, visto que o mesmo é 
entendido como o valor final de uma aplicação, ou seja, um valor inicial destinado à alguma transação financeira acrescido dos juros decorrentes deste processo e (b) o aluno não soube responder. Desta forma, pôde-se perceber que, na primeira entrevista, três alunos souberam responder adequadamente a definição de montante conforme a dimensão (a) - "Montante é o dinheiro que sobra no final', aluno D - e sete alunos não souberam responder (dimensão b). Já na segunda entrevista, seis alunos souberam responder adequadamente (dimensão a) - "Juros mais capital, ou seja, o que pegou no empréstimo (valor emprestado) mais os juros", aluno B -, enquanto quatro continuaram sem saber responder (dimensão b).

A análise das respostas foi conceitual, nem todos os alunos responderam esse questionamento explicitando a fórmula do montante, porém houve quatro casos na segunda entrevista respondidos dessa forma. Então, pôde-se perceber que houve um avanço de três alunos que souberam responder adequadamente este conceito na segunda entrevista. Porém, como se trata de um conceito muito utilizado no dia a dia, mas com uma nomenclatura mais aplicada à matemática financeira, considera-se um avanço significativo, já que não se trata de avaliar apenas se o aluno associa o nome ao conceito, mas sim, se consegue compreender o efeito causado pelo conceito compreendido como montante. Obteve-se como conclusão o avanço conceitual de três, dos sete estudantes que haviam respondido de forma inadequada ou incompleta na primeira entrevista.

\section{- Pergunta 13: compreender o Que os alunos entendem por capital.}

Entende-se por capital o valor inicial de uma aplicação ou transação financeira a qual não há acréscimo de juros. Desta forma, as respostas foram separadas em duas dimensōes, sendo elas: (a) capital entendido como o valor inicial de uma aplicação e (b) não soube responder ou respondeu de forma inadequada.

Assim, se observou que, na primeira entrevista, quatro alunos souberam responder o conceito compreendido por capital, enquadrando-se na dimensão (a) - "É o dinheiro que tu pede emprestado, quando tu faz um investimento é o primeiro que tu usd", aluno B -, enquanto seis alunos não souberam responder ou responderam um conceito inadequado de capital. Na segunda entrevista, oito alunos souberam responder que capital era o valor inicial sem o acréscimo de juros, enquanto dois mantiveram-se sem saber responder. Embora o conceito 
adequado tenha sido apenas uma descrição da fórmula de montante, demonstraram saber aplicá-lo na matemática financeira.

Logo, pôde-se perceber que a maioria dos alunos conseguiram compreender adequadamente a forma acadêmica do conceito de capital na segunda entrevista. Este conceito está presente na vida dos estudantes, porém com uma nomenclatura proveniente da matemática financeira. Compreender o seu significado contribui para que o estudante consiga desenvolver seu senso crítico sobre questōes financeiras, com o auxílio da matemática financeira. O conceito de capital foi abordado de acordo com a matemática financeira durante as oficinas. Quando tratava-se do valor bruto, chamava-se de capital e quando tratava-se de um valor com decorrência de juros chamava-se de montante. Logo a conceituação de capital foi realizada de forma tecnicista, visando a compreensão da fórmula utilizada em matemática financeira. Sendo assim os alunos acabaram por conceituar e definir este termo desta forma, relacionando-o com o valor sem aplicação de juros, já que ao longo das oficinas, ao trabalhar com valores provenientes de tais condiçōes, foram induzidos a relacioná-los com o conceito capital. Obteve-se como conclusão o avanço conceitual de quatro dos seis estudantes que haviam respondido de forma inadequada ou incompleta na primeira entrevista.

\section{- Pergunta 14: COMPReEnder o QUe os AlunOS ENTENDEM POR INFLAÇÃO.}

Dividiu-se as respostas em duas dimensōes, uma das respostas conceituadas adequadamente, na qual os alunos conseguiam compreender que a inflação é a influência do poder de compra da moeda (a) e outra dimensāo, na qual enquadrou-se as respostas que os alunos não souberam responder (b).

Na primeira entrevista, um aluno, apenas, respondeu que inflação era a influência do poder de compra da moeda (dimensão a) - "É um tipo de imposto, não? Inflação... A inflação é o cálculo... ah... não é conforme vale a moeda do país, né?", aluno $\mathrm{H}$, enquanto os outros nove não souberam responder (dimensão b). Já na segunda entrevista, sete alunos conseguiram compreender que a inflação era a variação do poder de compra da moeda (dimensão a) - "É o valor que tem a moeda. Por exemplo, se o dólar aumenta, o produto vai aumentar o valor. É o poder de compra do dinheiro", aluno $\mathrm{H}$-, enquanto três mantiveram suas respostas, demonstrando que não compreenderam o que é inflação (dimensão b).

Neste questionamento, consegue-se perceber mais um avanço em relação à compreensão geral dos participantes da oficina. Isso é uma constatação 
importante, à medida que compreender o conceito de inflação contribui na formaçāo integral do aluno, já que os mesmos vivenciarão situaçōes influenciadas por este conceito no seu dia a dia. Obteve-se como conclusāo o avanço conceitual de seis dos nove estudantes que haviam respondido de forma inadequada ou incompleta na primeira entrevista.

\section{- Pergunta 15: COMPREENder o QUe OS ALUNOS ENTENDEM POR INVESTIMENTO.}

Este questionamento foi realizado com o intuito de compreender se os alunos entendiam a poupança como fonte de rendimento para que, assim, pudesse-se propor a reflexão, durante a oficina, acerca da rentabilidade da poupança. Ou seja, propor a reflexão crítica sobre render ou perder dinheiro, ao longo do tempo, ao investir na poupança.

Desta forma, pôde-se observar que, na primeira entrevista, sete alunos responderam que investir é ter um retorno financeiro no futuro (dimensāo a) - "É investir em algo que me dê algum retorno financeiro", aluno G -, enquanto dois alunos responderam que é gastar com lazer (dimensão b) - "É você ter um sonho $e$ investir naquilo que você quer. Tipo o que você precisa fazer para chegar até este sonho", aluno J - e um afirmou que investir é comprar algum bem material (dimensão c) - "Pra mim é. Por exemplo, eu ganho o meu salário no fim do mês e guardo ele pra fazer alguma coisa que eu queira, como uma viagem, uma carteira de motorista ou uma formatura", aluno $\mathrm{C}$-. As respostas mantiveram-se as mesmas nas duas entrevistas para todos os alunos entrevistados. Portanto, observou-se que os alunos possuem diferentes pontos de vista quando falamos em investimento. Nem todos entendem investimento somente como ganhar dinheiro. Alguns, por sua vez, entendem que investir é também cuidar da sua saúde física e mental, por exemplo, quando abordam o investimento em lazer, bem como aqueles que entendem que investir é comprar algum bem material. Assim, houve pouco avanço conceitual dos estudantes que haviam respondido de forma inadequada, no sentido acadêmico, ou incompleta na primeira entrevista e assim permaneceram. Porém, durante a análise dos dados, pôde-se perceber que o avanço pretendido inicialmente com este questionamento não foi atingido justamente porque os conceitos de investimentos abordados pelos estudantes, mesmo que diferentes do conceito acadêmico visto em matemática financeira, não estava incorreto. Sendo assim os alunos mantiveram seu ponto de vista na segunda entrevista, acerca de investimento, por ter sido abordado, ao longo da oficina, de forma a credibilizar seu entendimento sobre investimento. 
- Pergunta 16: COMPREender Se os alunos CONSideram que os CONCEITOS ANTERIORMENTE QUESTIONADOS PODEM ESTAR RELACIONADOS COM A VENDA DE PRODUTOS E DE SERVIÇOS.

Isso, porque, era necessário constatar se os alunos entendiam que estes conceitos estão relacionados com o trabalho que foi realizado durante a oficina e com as suas atividades financeiras cotidianas, já que os mesmos fazem compras de produtos e contratam serviços. Contudo, todos os estudantes entrevistados responderam que estes conceitos estão relacionados com a venda em ambas as entrevistas.

\section{- Pergunta 17: aVeriguar Se os alunos acham que entender estes CONCEITOS PODE CONTRIBUIR NA SUA VIDA PESSOAL E PROFISSIONAL APÓS A ESCOLA.}

Pretendeu-se verificar o interesse dos alunos pelas discussōes que seriam propostas ao longo da oficina, quando realizada a primeira entrevista. E, ao término das oficinas, os estudantes foram novamente questionados para que, assim, pudesse-se compreender se, de fato, os estudantes consideram o aprendizado destes conceitos importantes para a sua vida fora da escola.

Como resposta a este questionamento, todos os alunos responderam que sim, que acreditam que estes conceitos têm importância para a sua vida após a escola, em ambas as entrevistas. Na primeira entrevista, dois alunos responderam que os conceitos poderiam auxiliar no vestibular ou mesmo na escola, cinco alunos responderam que poderiam auxiliar nas suas vidas profissionais, enquanto três alunos responderam que poderiam auxiliar na vida, na hora de realizar uma compra, por exemplo. Na segunda entrevista, três alunos responderam que auxilia no âmbito profissional, enquanto sete responderam que auxilia na sua vida pessoal. Um exemplo dessa constatação é a fala do Aluno E que diz que "com certeza, isso [conteúdos de matemática financeira] deveria ter desde o ensino fundamental. Várias pessoas sofrem por isso, tem medo da vida financeira, chega o fim do mês e já se desespera. As pessoas saberiam se planejar mais futuramente". 
- Pergunta 18: AVERIGuar Se OS eStudantes Se Sentiam Seguros em tOMAR UMA DECISÃO DE COMPRA E SE SABEM QUANDO É MAIS VANTAJOSO COMPRAR ALGO À VISTA OU A PRAZO.

Uma das hipóteses para a primeira entrevista realizada com os estudantes é que responderiam que é sempre mais vantajoso comprar algo à vista e, após a reflexão sobre esta questão e a discussão sobre inflação, esperava-se que os participantes mudassem de opiniāo em relação à primeira resposta.

Desta forma, constatou-se que, na primeira entrevista, nove estudantes responderam que tinham segurança em realizar uma compra e um aluno respondeu que não se sentia seguro. Na segunda entrevista, oito alunos responderam que se sentiam seguros em efetuar uma compra e dois responderam que não. Em geral, as respostas mantiveram-se as mesmas para o primeiro questionamento, quando o objetivo era compreender se os alunos se sentiam seguros para tomar decisōes de compras. Porém, um único aluno trocou sua posiçāo em relação a este questionamento, para a resposta em que o mesmo deixa explícito que não se sente seguro para realizar uma decisão de compra, ele pode ter refletido sobre sua posição anterior e ter percebido que é necessário um planejamento prévio de suas finanças que até o momento não foi feito.

Agora, na segunda etapa do questionamento, quando perguntado aos alunos se sabem quando é mais vantajoso comprar à vista ou a prazo, observou-se que na primeira entrevista a maioria dos alunos responderam que a compra à vista era mais vantajosa, como por exemplo, a fala do Aluno G, que diz, na primeira entrevista, que "vale a pena comprar à vista. Muito mais a pena. Vale porque, em primeiro lugar, não tem juros e também parcelado eles cobram a mais. Também porque tu não ficas todo mês pagando, pagando, pagando". Enquanto isso, na segunda entrevista, a maioria dos alunos disse que se deve analisar cada caso, como foi discutido durante a realização dos encontros. Pode-se exemplificar essa afirmação através da fala do Aluno $G$, na segunda entrevista, o qual diz que "sim, a gente discutiu bastante sobre isso. A gente percebeu que depende do lugar que compramos, tem lugares sem juros que vale mais a pena que comprar à vista. Depois da oficina mudou, sempre preferia comprar à vista". 


\section{- Pergunta 19: Saber Se os alunos Consideram que SABem administrar SEU DINHEIRO.}

Apenas um aluno respondeu, na primeira entrevista, que não sabia administrar seu dinheiro e mudou sua resposta na segunda entrevista, indicando que sabe administrar seus ganhos e gastos. No entanto, sete alunos que responderam na primeira entrevista que já sabiam gerenciar seus gastos permaneceram com a resposta na segunda entrevista. Além disso, dois estudantes que responderam que não sabiam administrar suas finanças, na primeira entrevista, permaneceram com a resposta na segunda.

Pode-se concluir que a maioria dos estudantes já sabia administrar suas dívidas antes das oficinas pois, por tratar-se de alunos que estudavam à noite, todos os alunos entrevistados trabalhavam e recebiam seu próprio dinheiro. Deste modo, os mesmos já tinham uma vida ativa nos gastos e por isso, aprenderam a gerenciar suas dívidas.

Constatou-se também que alguns alunos responderam que as oficinas auxiliaram na reflexão de algumas problemáticas trazidas nos encontros, como, por exemplo, a primeira e a segunda resposta dadas a este questionamento pelo Aluno E. Na primeira entrevista, ao ser questionado se sabe gerenciar seu próprio dinheiro, o aluno responde: "Sim. Primeiro eu vejo o gasto que eu vou ter de todos os meses, vejo o quanto vai me sobrar, separo aquele dinheiro que tem aquele custo mensal, o que sobra eu gasto ou reinvisto em algo que eu já tinha investido e o resto eu guardo". Já na segunda entrevista, o mesmo aluno responde ao ser questionado se sabe gerenciar suas finanças com "sim. Consigo me organizar melhor, a questão de me planejar aconteceu um pouco antes, foi por isso que me interessei pela oficina, agregou no que eu estava pensando em fazer".

Optou-se por não trazer as discussōes para o capítulo de apresentação dos resultados. Ou seja, o referencial teórico nāo compôs a descrição individual das perguntas porque optou-se, primeiramente, em descrever os resultados para que o leitor possa tirar suas próprias conclusōes individuais durante a apresentação das mesmas. Sendo assim, o referencial teórico será discutido de forma integrada com a análise geral das questōes na próxima seção. 


\section{DISCUSSĀO GERAL}

De modo geral, para se concluir sobre a primeira hipótese, de que a educação financeira contribuiu com o desenvolvimento do senso crítico do aluno para questōes financeiras, percebeu-se uma evolução significativa na compreensão dos conceitos respondidos entre a primeira e a última entrevista. Com isso, conclui-se que sim, os alunos passaram a compreender melhor os conceitos trabalhados e, desta forma, puderam refletir antes de agir, compreendendo como se organizar financeiramente.

Como Freire (2014) aborda em sua obra, houve o processo de ensino, no qual o professor e o aluno adquiriram conhecimentos que estão em constante vivência. Do mesmo modo, pôde-se perceber que, conforme Costa (2009), esta prática de educação financeira contribuiu para o processo de aprender a aprender dos alunos, fazendo com que estes conceitos, constantemente vivenciados por eles, ajudem a compreender um pouco o mundo financeiro para que se tornem empreendedores de si mesmo (Vargas, 2012), ao refletir sobre os motivos para realizar um planejamento financeiro.

Para a segunda hipótese levantada neste trabalho, de que a educação financeira contribuiu para o desenvolvimento do raciocínio lógico dos estudantes, considerou-se as questōes 2, 5, 7, 8 e 9, já que as mesmas tratavam de situaçōes em que os estudantes deveriam desenvolver formas de solucioná-las envolvendo alguns conceitos abordados durante a oficina. Logo, como em todas as perguntas selecionadas para constatar esta hipótese, houve evoluçōes no desenvolvimento dos estudantes, concluiu-se que os participantes passaram a desenvolver fórmulas próprias para a resolução de problemas que surgiram ao longo das atividades desenvolvidas. Consegue-se perceber que os alunos, de fato, aprenderam os conceitos trabalhados, já que foram constatadas evoluçōes no desenvolvimento do raciocínio lógico dos estudantes. Isso porque, como é discutido por Becker (2012) e Hofmann e Soares (2015), os alunos puderam agir e refletir sobre os problemas apresentados durante a oficina, fazendo com que, esta ação sobre o objeto estudado, forme o conhecimento adquirido pelos alunos acerca dos conceitos trabalhados.

E a terceira hipótese levantada para este trabalho, de que a educação financeira contribuiu para o desenvolvimento autônomo e empreendedor do estudante, foi analisada a partir das questōes 17, 18 e 19, nas quais pode-se constatar que os estudantes desenvolveram sua independência para tomar suas decisōes financeiras. Porém, como houve um retrocesso dos estudantes na 
autoconfiança em gerenciar suas finanças, conclui-se que a educação financeira não contribuiu para o desenvolvimento autônomo imediato do estudante em relação às suas transaçōes financeiras, ou, pelo menos, que ela os incentivou a refletir mais sobre isso, gerando maior dúvida ao tomar decisōes financeiras. Assim como Rossetto (2019) reafirma através da Educação Financeira Crítica - a qual defende o desenvolvimento do senso crítico financeiro dos alunos na escola - os estudantes tornam-se mais prudentes em tomar decisōes financeiras e desenvolvem-se ao longo do processo de educar-se financeiramente, o que implica na contribuição direta de situaçōes reais da sua vida financeira.

Entretanto, pôde-se identificar uma acentuação no desenvolvimento do senso crítico do educando fazendo com que se possa interpretar este retrocesso como uma análise crítica sobre sua prática existente até o momento. Isso contribui para concluir que a educação financeira deve ser desenvolvida ao longo da formação do jovem, já que um curto espaço de tempo para a discussão destes assuntos, faz com que o estudante reflita sobre sua prática, mas não a modifique completamente. Como traz Pontes (2017), a educação financeira aplicada desde a infância contribui para a formação integral do estudante, já que quando abordada com alunos academicamente mais avançados, como estudantes do ensino médio, podem ter adquirido vícios financeiros os quais dificultam seu desvinculamento.

\section{CONSIDERAÇÕES FINAIS}

Tornou-se importante realizar esta pesquisa justamente por proporcionar uma reflexão acerca das práticas realizadas nas escolas atualmente. Isso porque o capitalismo vem proporcionando o desenvolvimento de uma cultura de consumo motivada pelo impulso e por desejos, sem que se tenha um planejamento prévio dos gastos para evitar o endividamento. Desta forma, é importante refletir sobre o contexto da educação financeira, bem como o modo como projetos que envolvem essa temática possam ser trabalhados, para que se possa pensar em uma proposta educativa inserida no contexto dos alunos.

Ao entender melhor o contexto que favoreceu a inserção da educação financeira no ensino básico, ou mais precisamente na nova BNCC, compreendeu-se a importância de práticas educativas voltadas a esta temática para a formação integral do estudante. Para justificar a assertiva anterior, a BNCC discute a educação financeira juntamente com as ideias empreendedoras, afirmando que a 
formação integral do aluno, ao trabalhar estas temáticas, se dará de modo a ocorrer a sua "inserçāo crítica e consciente no mundo atual" (Brasil, 2018, p. 568).

A escola entra como peça principal para a provocação dessas reflexōes, através da educação financeira, permitindo que os alunos conheçam os conceitos abordados na matemática financeira, como conteúdo programático a ser ensinado nas escolas. Porém, a educação financeira aproxima estes conceitos da vida cotidiana dos alunos, fazendo com que reflitam de fato sobre seus ganhos e gastos. Como a educação financeira visa proporcionar um espaço para o desenvolvimento do senso crítico do aluno do ensino básico, torna-se necessário ter cautela no desenvolvimento das atividades para que elas realmente possam proporcionar meios de desenvolver esse tema com o estudante, já que educar financeiramente envolve noçōes econômicas que vai além dos conceitos de matemática financeira previstos (Hofmann, 2020). Além disso, a BNCC (2018) aborda essa temática no meio escolar de forma interdisciplinar que vai muito além das aulas de matemática.

De forma geral, foi possível discutir e compreender, juntamente com o referencial teórico abordado nesta pesquisa, a importância de educar financeiramente os jovens na escola, já que muitas vezes os mesmos não têm contato com esse tipo de educação por parte das suas famílias. Além disso, pôde-se compreender o modo como essa temática pode ser abordada no âmbito escolar, utilizando-se o conceito empreendedor de si mesmo, contextualizado por Vargas (2012) e em concordância com o que foi discutido por Costa (2009), que afirmou que estas duas temáticas podem ser trabalhadas como o auxiliar no processo de aprender a aprender. Este processo que é discutido na pedagogia construtivista e explicada por Becker (2012) quando trata de interação entre sujeito e objeto na compreensão de conceitos.

Os resultados descritos indicam que é possível desenvolver educação financeira na escola, de modo que os conceitos podem ser compreendidos a partir da ação dos alunos sobre as decisōes financeiras que devem ser tomadas em um trabalho empreendedor. Assim, pode-se afirmar que a educação financeira contribuiu para o desenvolvimento do senso crítico do aluno perante a gestāo das suas finanças e o desenvolvimento do seu raciocínio lógico, que contribuiu para que o estudante desenvolva a capacidade de resolver problemas cotidianos.

Constatou-se, como proposta para novos estudos na área desta pesquisa, que, para enfatizar a distinção entre o que é feito nas escolas e a proposta apresentada pela BNCC, poderia ser realizada uma pesquisa nacional quantitativa para compreender quantas escolas atualmente trabalham com projetos 
de educação financeira para os estudantes. Logo, para avaliar uma aplicação de projeto de educação financeira e, assim, analisar a proposta trazida pela BNCC, foi realizado neste trabalho uma oficina, que abordou conceitos existentes na vida cotidiana do educando, através de um projeto de educação financeira a partir do empreendedorismo, a qual objetivava o desenvolvimento do raciocínio lógico do estudante ao trabalhar em grupo com uma abordagem construtivista e da sua autonomia financeira (futura) ao pensar criticamente sobre essa temática.

A abordagem deste projeto contribuiu para que os alunos se interessassem em refletir criticamente sobre os conceitos que envolvem suas transaçōes financeiras pessoais. Do mesmo modo como verifica Vargas (2012) ao dizer que o projeto é base para formaçāo do estudante, juntamente com o empreendedorismo, formando-o empreendedor de si mesmo. (Vargas, 2012). Em vista disso, a evolução no desenvolvimento dos estudantes em relação aos conceitos de educação financeira e as opiniōes dos mesmos quanto à importância da reflexão crítica dos conceitos trabalhados mostra o que diz na BNCC, que há hoje mais espaço para o desenvolvimento de atividades que abordam o empreendedorismo individual, em todas as classes sociais. Isso porque pôde-se verificar a necessidade dos alunos em compreender alguns conceitos que estão presentes no seu cotidiano e formá-los para a vida em sociedade.

\section{REFERÊNCIAS}

Becker, F. (2012). Educação e construção do conhecimento. $2^{\underline{a}}$ ed. Porto Alegre: Penso. Brasil. (2019). Resolução CNE/CP no 2, de 22 de dezembro de 2017. Institui e orienta a implementaçāo da Base Nacional Comum Curricular. Brasília, 2017. http://portal.mec. gov.br/index.php?option=com_docman\&view=download\&alias=79631-rcp002-17-pdf\&category_slug=dezembro-2017-pdf\&ltemid=30192. Acesso em 14 de jun. 2019.

Brasil. (2018). Ministério da Educaçāo. Base Nacional Comum Curricular. Brasília, 2018. http://basenacionalcomum.mec.gov.br/. Acesso em 30 de ago. 2018.

Brasil. (2018). Ministério da Educaçāo. Base Nacional Comum Curricular: ensino médio. Brasília, 2018. http://portal.mec.gov.br/index.php?option=com_docman\&view=download\&alias=85121-bncc-ensino-medio\&category_slug=abril-2018-pdf\&ltemid=30192. Acesso em 21 de jun. 2019.

Costa, S. S. G. (2009). Governamentalidade Neoliberal, Teoria do Capital Humano e empreendedorismo. Revista Educação \& Realidade, 34(2), 171-186. 
Freire, P. (2014). Pedagogia da Autonomia. 48aㅡ ed. Paz e Terra, 2014.

Hofmann, R. M., y Soares, M. T. C. (2015). Estratégias de educação financeira para crianças: construindo situaçōes didáticas de economia em sala de aula. Revista Atos de Pesquisa em Educaçāo. 10(1), 260-279.

Hofmann, R. M. (2020). Os Vieses Cognitivos e suas Implicaçōes para Educaçāo Financeira: o caso do "efeito Brumadinho" na construçāo de gráficos. Revista Bolema. 34(67), 564-582.

Pizzani, L., Silva, R. C. de, Bello, S. F., y Hayashi, M. C. P. I. (2012). A arte da pesquisa bibliográfica na busca do conhecimento. Revista Digital de Biblioteconomia e Ciência da Informação. 10(1), 53-66.

Pontes, A. N.; Tomazela, M. G. J. M. y Alves D. C. (2017). Nico: aplicativo para auxiliar na educação financeira de crianças do ensino fundamental. Revista Fatec Zona Sul. 4(1), 19-31.

Rossetto, J. C. (2019). Educaçāo financeira crítica: a gestāo do orçamento familiar por meio de uma prática pedagógica na educaçāo de jovens e adultos. Dissertaçāo (Mestrado em Ensino de Ciências Exatas) - Programa de pós-graduaçāo em Ensino de Ciências Exatas. Universidade do Vale do Taquari - Univates, Lajeado.

Silva, A. M. y Powell A. B. (2013). Um programa de educaçāo financeira para a matemática escolar da educação básica. Encontro Nacional de Educação Matemática. Curitiba. Anais... SBEM. pp. 18-21.

Vargas, P. R. R. (2012). Um estudo sobre educaçāo financeira e instituição escolar. (Tese Doutorado em Educaçāo) - Programa de pós-graduaçāo em Educaçāo. Universidade do Vale do Rio dos Sinos, São Leopoldo.

\section{CAMILA LABRES NEMOS}

Dirección: $\quad$ Rua Henrique Stefani, 1110 (casa 19), bairro Igara - CEP: 92.412-216

Canoas, Rio Grande do Sul, Brasil.

camilanemos@gmail.com

Telefone: $\quad$ +55 (51) 989323353 